\title{
Mapping hydrological environments in central Amazonia: ground validation and surface model based on SRTM DEM data corrected for deforestation
}

\author{
G. M. Moulatlet ${ }^{1,3}$, C. D. Rennó ${ }^{2}$, F. R. C. Costa $^{3}$, T. Emilio ${ }^{3}$, and J. Schietti ${ }^{3}$ \\ ${ }^{1}$ Department of Biology, University of Turku, Turku, Finland \\ ${ }^{2}$ Instituto Nacional de Pesquisas Espaciais, Avenida dos Astronautas, 1758, CEP 12227-010, \\ São José dos Campos, Brazil \\ ${ }^{3}$ Instituto Nacional de Pesquisas da Amazônia, Avenida André Araújo, 2936, CP 478, CEP 69011-970, \\ Manaus, Brazil
}

Correspondence to: G. M. Moulatlet (gabriel.moulatlet@utu.fi)

Received: 23 June 2014 - Published in Earth Syst. Sci. Data Discuss.: 25 July 2014

Revised: 23 February 2015 - Accepted: 24 February 2015 - Published: 12 March 2015

\begin{abstract}
One of the most important freely available digital elevation models (DEMs) for Amazonia is the one obtained by the Shuttle Radar Topography Mission (SRTM). However, since SRTM tends to represent the vegetation surface instead of the ground surface, the broad use of SRTM DEM as a framework for terrain description in Amazonia is hampered by the presence of deforested areas. We present here two data sets: (1) a deforestationcorrected SRTM DEM for the interfluve between the Purus and Madeira rivers, in central Amazonia, which passed through a careful identification of different environments and has deforestation features corrected by a new method of increasing pixel values of the DEM (Rennó, 2009); and (2) a set of 18 hydrological-topographic descriptors based on the corrected SRTM DEM. Deforestation features are related with the opening of an $800 \mathrm{~km}$ road in the central part of the interfluve and occupancy of its vicinity. We used topographic profiles from the pristine forest to the deforested feature to evaluate the recovery of the original canopy coverage by minimizing canopy height variation (corrections ranged from 1 to $38 \mathrm{~m}$ ). The hydrological-topographic description was obtained by the Height Above the Nearest Drainage (HAND) algorithm, which normalizes the terrain elevation (above sea level) by the elevation of the nearest hydrologically connected drainage. The validation of the HAND data set was done by in situ hydrological description of $110 \mathrm{~km}$ of walking trails also available in this data set. The new SRTM DEM expands the applicability of SRTM data for landscape modelling; the data sets of hydrological features based on topographic modelling are undoubtedly appropriate for ecological modelling and an important contribution to environmental mapping of Amazonia. The deforestation-corrected SRTM DEM is available at http://ppbio.inpa.gov.br/knb/metacat/naman.318.3/ppbio; the polygons selected for deforestation correction are available at http://ppbio.inpa.gov.br/knb/metacat/naman.317.3/ppbio; the set of hydrological-topographic descriptors is available at http://ppbio.inpa.gov.br/knb/metacat/naman.544.2/ppbio; the environmental description of access trails is available at http://ppbio.inpa.gov.br/knb/metacat $/$ naman.541.2/ppbio; and the limits of deforestation corrections and drainage validation are available at http://ppbio.inpa.gov.br/knb/metacat/liliandias.38.1/ ppbio.
\end{abstract}




\section{Introduction}

Environmental mapping in the $6000000 \mathrm{~km}^{2}$ of the Amazon basin remains one of the major challenges in tropical research. Remote forests lack reliable environmental data sets at scales that allow detailed studies due to difficulties in access, monitoring and collecting information. The apparent homogeneity of the forest canopy as seen from above comprises a mosaic of different environments, which can be detected by the ongoing use of remote sensing data and geographic information system (GIS) metrics as descriptors of environmental variation in those remote areas. Among the descriptors, digital elevation models (DEMs) have been shown to be a reliable data source for terrain description in Amazonia because terrain features derived from DEMs can be strongly correlated with soil properties and hydrology (Rennó et al., 2008; Nobre et al., 2011). Global elevation data at high spatial resolution (approximately $90 \mathrm{~m}$ ) became easily available after the Shuttle Radar Topographic Mission (SRTM) in 2000. Since then, the SRTM DEM has been widely used to map and classify environments in Amazonia (Salovaara et al., 2005; Valeriano et al., 2006; Bispo et al., 2009; Valeriano and Rossetti, 2010).

In dense tropical forests, the topographic detail provided by SRTM should be interpreted carefully because the Cband radar used to obtain the DEM interacts in a complex way with the dense forest canopy (Kellndorfer et al., 2004). Over Amazonian forests, the SRTM DEM should therefore be considered as a digital surface model, rather than an elevation model, resulting in a reduced detectability of important terrain features hidden by the dense canopy (Valeriano and Rossetti, 2012). An innovative method to extract hydrological features under the dense forest canopy was proposed by Rennó et al. (2008). The authors developed the Height Above the Nearest Drainage (HAND) algorithm, which calculates a terrain descriptor that represents the vertical distance of each point of the terrain to the nearest drainage network. This terrain descriptor can be interpreted as the local drainage potential (Rennó et al., 2008). The algorithm produces a new DEM where the values represent altitudes relative to the local drainage instead of the sea level. However, the applicability of the HAND approach for a large extent of Amazonia is hampered by the presence of deforested areas, where the original vegetation cover was either degraded or replaced by pasture and abandoned afterwards, converted into a mosaic of secondary forests with different regeneration ages. In practice, these areas are interpreted by HAND as depressions, generating false drainage channels and resulting in misestimation of HAND values in areas around these channels.

In our data set we provide a new SRTM DEM on which deforestation features were corrected based on PRODES (Amazonian Deforestation Monitoring Project; INPE, 2002) accumulated deforestation database. PRODES information was used to identify deforested areas on the original SRTM that could act as depressions to the HAND algorithm. We also present HAND grids using 18 different drainage networks automatically extracted from the corrected DEM. The HAND algorithm was initially tested in topographically dissected areas in central Amazonia (Nobre et al., 2011), but it also proved to be efficient in large flat areas (Moulatlet et al., 2014). The data set presented in this paper mitigates the lack of reliable data to be used as base for hydrological modelling for the interfluve of the Purus and Madeira rivers, two important contributors to the Amazon River. This data set can also be broadly used for ecological modelling and is an important contribution for mapping Amazonian lowland forests.

\section{Data}

\subsection{Study site}

The data set covers a large area of dense tropical forests in Central Amazonia, delimited by the Purus river in the west, Madeira river in the east and Solimões river in the north (Fig. 1). The interfluve has flat terrains, with relatively low altitudes ( 27 to $80 \mathrm{~m}$ a.s.l on the corrected polygon SRTM) and has seasonally imperfectly drained soils (Sombroek, 2000). Three geomorphologies are found: alluvial terraces, mega-slopes and mega-plateaus (Brasil, 1978), each with particular hydrological dynamics related to the soil type and proximity of the large rivers. Mega-plateaus and riverine terraces are subject to flooding, caused by overflow of major tributaries of the Amazon River and by saturation of soil at the end of the rainy season (December-July). Mega-slopes present higher altitudes and well-drained terrains. The main soil types are Plinthosols on mega-plateaus and mega-slopes and Fluvisols on alluvial terraces (Quesada et al., 2011).

\subsection{Reducing deforestation features on the SRTM DEM}

The deforestation-corrected SRTM DEM for the PurusMadeira interfluve has the deforestation features (Fig. 2) replaced by non-deforested ones. The correction process consists in raising pixel values of the SRTM DEM at pre-selected areas and further evaluation of the results by the analysis of topographic profiles from non-deforested areas to the corrected areas (Fig. 1). The selection and delimitation of deforested areas were done by the use of the accumulated information available in the data set of the PRODES project, which contains deforestation information collected by intense monitoring of Amazonia since 1988. This information is especially useful in the Purus-Madeira interfluve, where the identification of deforested areas is not obvious. After abandonment, deforested areas may become secondary forests at different regeneration levels, making the identification of these areas complex in the mosaic of forest types found in the interfluve Purus-Madeira. Moreover, open areas of savanna can be found growing in the middle of the forest (Fig. 2). 


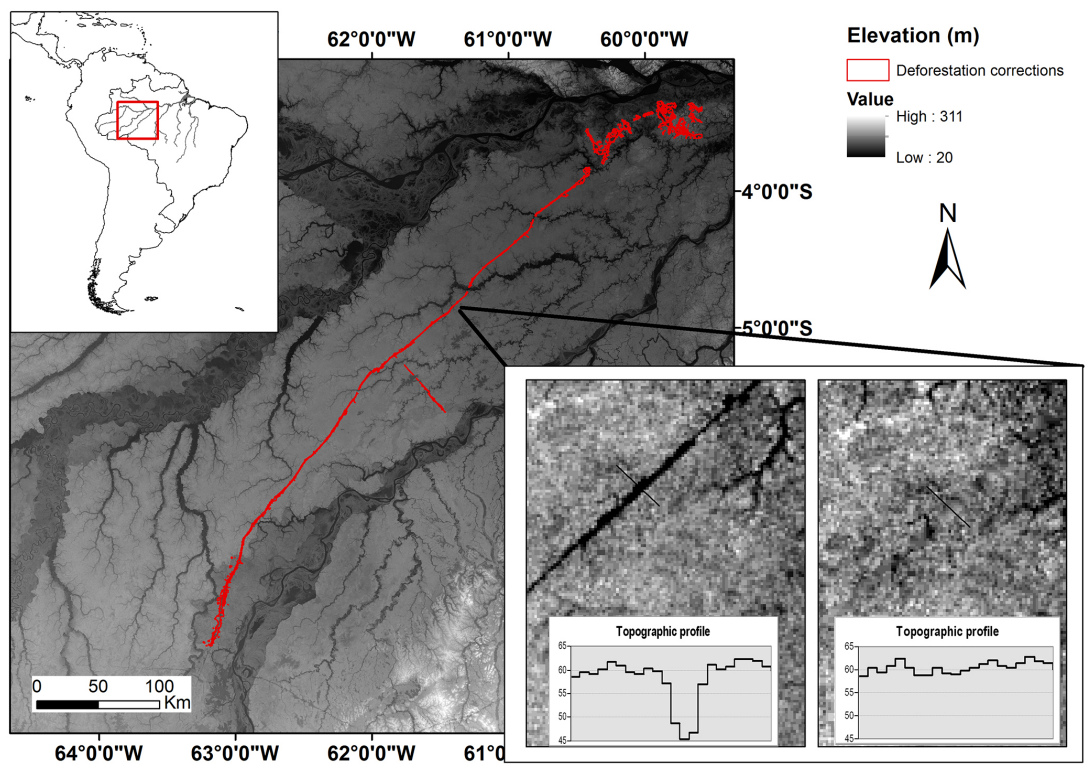

Figure 1. Study area. The grey scale represents the elevation values in metres from the SRTM-DEM data. The inner box shows the comparison between the original SRTM-DEM and the new SRTM-DEM with deforestation features corrected. Both topographic profiles are shown in the graphs. Red polygons indicate the areas where the deforestation correction was done.

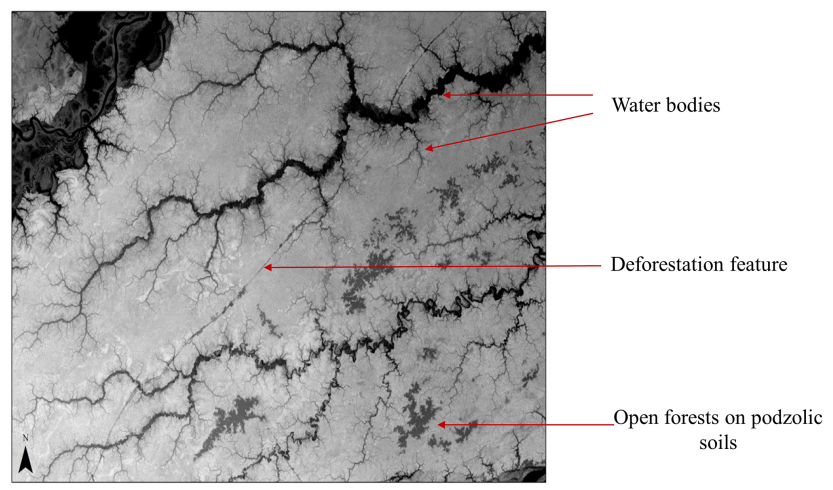

Figure 2. Arrows indicate three important terrain features for interpretation of the SRTM. The image shows that deforestation has the same grey colour pattern as rivers and open forests.

PRODES data is acquired from Landsat/CBERS imagery with a spatial resolution of $30 \mathrm{~m}$.

The deforestation correction was done using the program DEM_CORR (Rennó, 2009) implemented in IDL/ENVI, which provides tools to add or subtract elevation values of each pixel of the SRTM DEM. The criterion for adding back values to the pixels is based on the canopy height of the primary forests. Elevation profiles from the primary forest to the deforested features are used to evaluate the recovery of the canopy height (pixel corrections ranged from 1 to $38 \mathrm{~m}$ ). As a result, each pixel in deforested areas is assigned a new elevation, recovering the supposed original forest coverage. The original coverage of the patches of vegetation in vari- able regeneration stages was much more challenging to restore by our correction method than areas where forest was cut at ground level, since the variation of the pixels' values on these large regenerating patches is higher. We decided not to correct open areas of savannas because they have irregular borders and large dimensions, which would make the correction process long, and the results could not be satisfactory by the use of our methodology.

The deforestation-corrected SRTM DEM product has a spatial resolution of 3 arcseconds (approximately $90 \mathrm{~m}$ close to Ecuador), measuring 7200 columns by 6000 rows, and is available in geoTIFF format. The polygon including corrected areas $\left(61^{\circ} 71^{\prime} \mathrm{W}, 05^{\circ} 09^{\prime} \mathrm{S}\right)$ is available in shapefile format. Areas outside the limits of the polygon were not corrected.

\subsection{Drainage network extraction and hydrological modelling}

The main aim of the correction on the SRTM DEM is to avoid the identification of false drainage channels by the HAND algorithm, caused by deforestation features (Fig. 2). Drainage extraction is a process dependent on the preceding determination of flow directions in a DEM, given that topographic features drive the directions of water flow on the terrain. Flow direction in a landscape is defined by the elevation difference between one point of the terrain and the nearest point in the drainage to which the focal point is hydrologically connected. The first stage of the drainage extraction is the definition of the local flow directions and the determination of the accumulated area, automatically extracted by computa- 
tional procedures. Extractions made here followed the protocol described in Rennó et al. (2008). The following step is the definition of the contributing area threshold, which indicates the number of contributing pixels necessary to initiate one drainage channel. The higher the threshold value, the lower is the density of the drainage network. We selected 18 thresholds $(10,20,30,40,50,100,150,200,250,300,350$, $400,500,600,700,800,900$ and 1000) that provided different densities of drainage networks. Then for each of the 18 drainage networks we calculated the vertical distance to the nearest drainage by the HAND algorithm, which resulted in 18 HAND grids for the study area.

HAND normalizes pixel altitudinal values by changing their reference from sea level to the nearest drainage. This is the hydrologically connected nearest drainage, not necessarily the one with the lowest Euclidian distance. As a result, local drainage will have an elevation of zero metres, independent of their elevation above sea level. The pixels in the neighbourhood will be assigned new values according to the nearest drainage. HAND values close to zero indicate areas where the water table is close to the surface (saturated areas), whereas high values indicate a deep water table (well-drained areas). HAND is a stationary measure and does not vary according to seasonal variation. It represents the local draining potential of the terrain independent of the season and rainfall variations. The HAND normalization reveals heterogeneous landscapes hidden in the SRTM DEM based on the draining potential of each pixel (Fig. 3). HAND has been used as hydrological descriptor because of its capability to describe hydrological environments based on the distance of each pixel of a DEM to the water table (Nobre et al., 2011; Gharari et al., 2011; Schietti et al., 2013).

The 18 selected thresholds allowed the extraction of 18 HAND grids. The use of different thresholds is an attempt to encompass the variety of terrain types found in the PurusMadeira interfluve, because different geomorphologies may be sensitive for specific drainage thresholds. Therefore, the set of thresholds allows the choice of the most suitable data for different types of studies and environments.

\subsection{Ground truth data}

We also provided field data obtained along more than $110 \mathrm{~km}$ of walking trails inside the forest that contain a qualitative description of the environments along the trails (Table 1). We described environments categorizing the soil drainage conditions approximately every $90 \mathrm{~m}$ and recorded the presence of all small streams, which are usually undetectable in the SRTM DEM. These environments were identified between August 2010 and February 2011 and include eight classes of hydrological environments, from well-drained to inundated areas. For each description point we recorded the geographical coordinates in order to provide information to validate the choice of drainage thresholds.
Table 1. Structure of the table describing the geographical coordinates of the main hydrological features along $110 \mathrm{~km}$ of walking trails in the research plots of the Brazilian Program of Biodiversity (PPBio) and adjacent trails placed along the interfluve PurusMadeira. The field name columns contain the information taken along the trails. The original table is available in a shapefile format at http://ppbio.inpa.gov.br/knb/metacat/naman.541.2/ppbio.

\begin{tabular}{ll}
\hline Field name & Description \\
\hline Site & $\begin{array}{l}\text { Site name of plots along the interfluve } \\
\text { Purus-Madeira }\end{array}$ \\
Latitude & $\begin{array}{l}\text { Latitudinal coordinate format in decimal } \\
\text { degrees }\end{array}$ \\
Longitude & $\begin{array}{l}\text { Longitudinal coordinate format in deci- } \\
\text { mal degrees }\end{array}$ \\
Plot & $\begin{array}{l}\text { Plot identification along the interfluve } \\
\text { Main_Hydro }\end{array}$ \\
& $\begin{array}{l}\text { Main hydrological feature name. Hydro- } \\
\text { logical unit represented either by one wa- } \\
\text { ter body, such as streams, flooding areas, } \\
\text { or by a soil drainage condition. }\end{array}$ \\
\hline
\end{tabular}

\section{Limitations of data use}

The data set provided here offers an important hydrological contextualization of topographic data from a deforestationcorrected SRTM by the provision of 18 hydrological models based on different drainage networks. It also allows a local adjustment of the hydrological models through field data validation. However, the data set should be used with caution in some applications, for four reasons. First, deforestation correction of large deforested patches is complex because of the high elevational variation in these areas. An attempt at correction of deforestation features in extremely deforested conditions can be seen in Rennó (2009). Second, drainage may be either overestimated or underestimated for some areas, depending on the chosen threshold, since there are no available methods that combine more than one threshold in the same HAND grid. Further studies are needed to provide methods of combination of thresholds in the calculation of the hydrological models. The 18 HANDs provided here attempt to overcome this problem. Additional environmental descriptors, such as soil drainage conditions and water table monitoring data, might also clarify the choice of the most suitable drainage network for specific areas. Third, large areas of the Purus-Madeira interfluve are subject to flooding by the larger rivers of the basin. Flooding is an important environmental characteristic not taken into account in our hydrological modelling. HAND represents the local draining potential of each pixel of the SRTM DEM, but in flooded areas this potential may be misinterpreted. Fourth, the resolution of the input data determines the scale for the HAND application. In this case, the model cannot be used at very local scales, where resolution below $90 \mathrm{~m}$ is required. 
SRTM

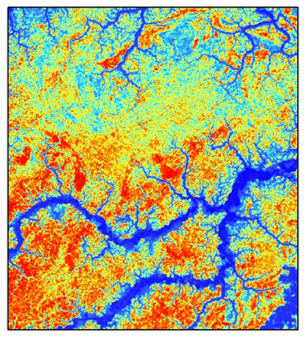

HAND 100

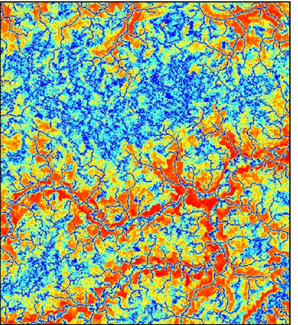

HAND 10

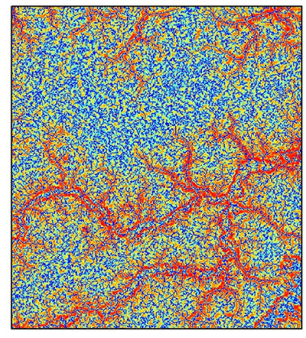

HAND 500

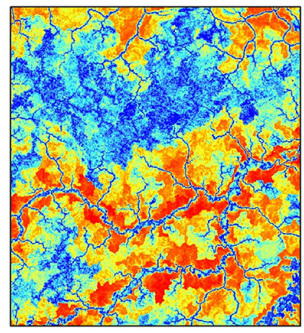

HAND 50

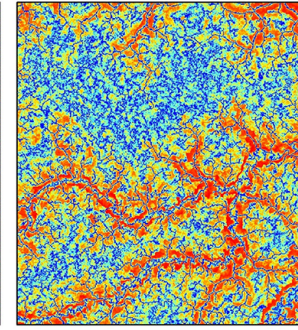

HAND 1000

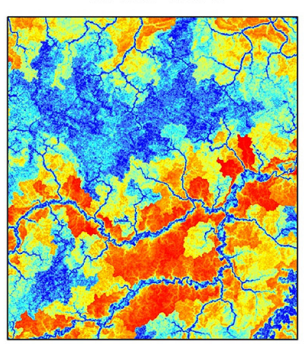

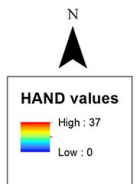

SRTM values

- High: 76

Figure 3. Comparisons among SRTM DEM and HAND DEM at five of the 18 drainage thresholds available. HAND values are indicators of the vertical distance of the terrain to the water table level and provide hydrological environments mapping, useful for ecological modelling over large extent areas. Threshold values (on the top of each HAND figure) were defined during the application of the HAND method and indicate the density of the drainage network based on the number of pixels contributing to the drainage channel initiation (the higher the threshold, the lower is the drainage density).

\section{Data set location and format}

All the data and metadata presented here are available at the permanent repository of data maintained by the Brazilian National Program of Research in Biodiversity (PPBio) (Pezzini et al., 2012) hosted at the National Institute for Amazonian Research (INPA) in Manaus, Brazil (http://ppbio.inpa.gov.br/ repositorio/dados). The new SRTM DEM and the set of 18 HAND images are available in geoTIFF format. The field description data, the polygon of corrected areas on the SRTMDEM and the polygon that limits areas without corrections or drainage validation are available as a shapefile.

\section{Data use and reuse}

We presented here the products of deforestation corrections on the SRTM DEM using PRODES data sets and a set of 18 hydrological-topographic descriptors (HAND) based on the corrected SRTM DEM. The effects of deforestation were minimized and allowed the application of a more reliable DEM for terrain modelling. The data set explicitly expresses the role of hydrology on the surface of the landscape. The deforestation-corrected SRTM DEM was already used in Martins et al. (2014) as a framework for extraction of topographic indexes. Cintra et al. (2013) and Moulatlet et al. (2014) extracted point values from the HAND with threshold of 50 as proxies for local hydrological conditions to describe woody biomass production and herbs species distribution, respectively. The applicability of the deforestation- corrected SRTM DEM and the HAND data set is not restricted to ecological studies: they can be used in any environmental modelling. The environmental description of the hydrological conditions contains useful information to plan ecological studies on central Amazonia and is especially important for validation of remote sensing products. The data help to fill the gaps in environmental data for Amazonia lowland forests. An extension of this methodology for other areas in Amazonia in the future would be an important step in the mapping of Amazonian forests.

Author contributions. G. M. Moulatlet prepared the manuscript with contribution of all co-authors; G. M. Moulatlet, T. Emilio and J. Schietti collected the data; C. D. Rennó developed the algorithm code and ran the analyses; G. M. Moulatlet, C. D. Rennó, F. R. C. Costa, T. Emilio, J. Schietti evaluated and validated the models.

Acknowledgements. We thank the FAPESP/FAPEAM/HIDROVEG (project no.006/2009, led by F.R.C.C.) and the PRONEX/FAPEAM/CNPq (project no. 16/2006, led by W. E. Magnusson, INPA) for financial support; G. M. Moulatlet had a master's scholarship provided by CNPq; we thank Livia Naman and Lilian Fernandes for the support from the PPBio data repository; and Jasper Van doninck and two anonymous referees for valuable comments on the manuscript.

Edited by: N. Verhoest 


\section{References}

Bispo, P. C., Valeriano, M. M., and Kuplich, T. M.: Relation of local geomorphometric variables with the vegetation of the Madeira-Purus interfluve (AM/RO), Acta Amazonica 39, 81-90, doi:10.1590/S0044-59672009000100008, 2009.

Brasil: Projeto Radambrasil. Folha SB.20 Purus; geologia, geomorfologia, pedologia, vegetação e uso potencial da terra, Mineral, D.N.P., Vol. 17, 566 pp., 1978.

Cintra, B. B. L., Schietti, J., Emillio, T., Martins, D., Moulatlet, G., Souza, P., Levis, C., Quesada, C. A., and Schöngart, J.: Soil physical restrictions and hydrology regulate stand age and wood biomass turnover rates of Purus-Madeira interfluvial wetlands in Amazonia, Biogeosciences, 10, 7759-7774, doi:10.5194/bg-107759-2013, 2013.

Gharari, S., Hrachowitz, M., Fenicia, F., and Savenije, H. H. G.: Hydrological landscape classification: investigating the performance of HAND based landscape classifications in a central European meso-scale catchment, Hydrol. Earth Syst. Sci., 15, 3275-3291, doi:10.5194/hess-15-3275-2011, 2011.

INPE (Instituto Nacional de Pesquisas Espaciais): Deforestation estimates in the Brazilian Amazon INPE, São José dos Campos, 2002, available at: http://www.obt.inpe.br/prodes/ (last access: 15 November 2013), 2002.

Kellndorfer, J., Walker, W., Pierce, L., Dobson, C., Fites, J. A., Hunsaker, C., Vona, J., and Clutter, M.: Vegetation height estimation from Shuttle Radar Topography Mission and National Elevation Datasets, Remote Sens. Environ., 93, 339-358, doi:10.1016/j.rse.2004.07.017, 2004.

Martins, D. L., Schietti, J., Feldpausch, T. R., Luizão, F. L., Phillips, O. L., Andrade, A., Castilho, C. V., Laurance, S. G., Oliveira, A., Amaral, I. L., Toledo, J. J., Lugli, L. F., Pinto, J. L. P. V., Mendoza, E. M. O., and Quesada, C. A.: Soil-induced impacts on forest structure drive coarse woody debris stocks across central Amazonia, Plant Ecology \& Diversity, 8, 229-241, doi:10.1080/17550874.2013.879942, 2014.

Moulatlet, G. M., Costa, F. R. C., Rennó, C. D., Emilio, T., and Schietti, J.: Local Hydrological Conditions Explain Floristic Composition in Lowland Amazonian Forests, Biotropica, 46, 395-403, doi:10.1111/btp.12117, 2014.

Nobre, A. D., Cuartas, L. A., Hodnett, M., Rennó, C. D., Rodrigues, G., Silveira, A., Waterloo, M., and Saleska, S.: Height Above the Nearest Drainage - a hydrologically relevant new terrain model, J. Hydrol., 404, 13-29, doi:10.1016/j.jhydrol.2011.03.051, 2011.

Pezzini, F. F., Melo, P. H .A., Oliveira, D. M. S., Amorim, R. X., Figueiredo, F. O. G., Drucker, D. P., Rodrigues, F. R. O., Zuquim, G., Emilio, T., Costa, F. R. C., Magnusson, W. E., Sampaio, A. F., Lima, A. P., Garcia, A. R. M., Manzatto, A. G., Nogueira, A., Costa, C. P., Barbosa, C. E. D. A., Castilho, C. B. C. V., Cunha, C. N., Freitas, C. G., Cavalcante, C. O., Brandão, D. O., Rodrigues, D. J., Santos, E. C. P. R., Baccaro, F. B., Ishida, F. Y., Carvalho, F. A., Moulatlet, G. M., Guillaumet, J. L. B., Pinto, J. L. P. V., Schietti, J., Vale, J. D., Belger, L., Verdade, L. M., Pansonato, M. P., Nascimento, M. T., Santos, M. C. V., Cunha, M. S., Arruda, R., Barbosa, R. I., Romero, R. L., Pansini, S., and Pimentel, T. P.: The Brazilian Program for Biodiversity Research (PPBio) Information System, Biodiversity \& Ecology, 4, 265-274, doi:10.7809/b-e.00083, 2012.
Quesada, C. A., Lloyd, J., Anderson, L. O., Fyllas, N. M., Schwarz, M., and Czimczik, C. I.: Soils of Amazonia with particular reference to the RAINFOR sites, Biogeosciences, 8, 1415-1440, doi:10.5194/bg-8-1415-2011, 2011.

Rennó, C. D.: Redução dos efeitos do desmatamento sobre modelo digital de elevação do SRTM usando imagem TM/LANDSAT, in: Simpósio brasileiro de sensoriamento remoto, 14. (SBSR), Natal. Anais. São José dos Campos: INPE, 2009, 7095-7102, DVD, ISBN 978-85-17-00044-7, available at: http://urlib.net/dpi.inpe. br/sbsr@80/2008/11.15.22.13, 2009.

Rennó, C. D., Nobre, A. D., Cuartas, L. A., Soares, J. V., Hodnett, M. G., Tomasella, J., and Waterloo, M.: HAND, a new terrain descriptor using SRTM-DEM; mapping terra-firme rainforest environments in Amazonia, Remote Sens. Environ., 112, 3469-3481, doi:10.1016/j.rse.2008.03.018, 2008.

Salovaara, K., Thessler, S., Malik, R. N., and Tuomisto, H.: Classification of Amazonian primary rain forest vegetation using Landsat ETM+ satellite imagery, Remote Sens. Environ., 97, 39-51, doi:10.1016/j.rse.2005.04.013, 2005.

Schietti, J., Emilio, T., Rennó, C. D., Drucker, D. P., Costa, F. R. C., Nogueira, A., Baccaro, F. B., Figueiredo, F. B., Castilho, C., Kinupp, V., Guillaumet, J. L., Garcia, A. D., Lima, A., and Magnusson, W. E.: Vertical distance from drainage drives floristic composition changes in an Amazonian rainforest, Plant Ecology \& Diversity, 7, 241-253, doi:10.1080/17550874.2013.783642, 2013.

Sombroek, W.: Amazon landforms and soil in relation to biological diversity, Acta Amazonica, 30, 81-100, 2000.

Valeriano, M. M. and Rossetti, D. F.: Topographic modeling of Marajó Island with SRTM data, Revista Brasileira de Geomorfologia, 9, 53-63, 2010.

Valeriano, M. M. and Rossetti, D. F.: Topodata: Brazilian full coverage refinement of SRTM data, Appl. Geogr., 32, 300-309, doi:10.1016/j.apgeog.2011.05.004, 2012.

Valeriano, M. M., Kuplich, T. M., Storino, M., Amaral, B. D., Mendes, J. N., and Lima, D. J.: Modeling small watersheds in Brazilian Amazonia with shuttle radar topographic mission-90 m data, Comput. Geosci., 32, 1169-118, doi:10.1016/j.cageo.2005.10.019, 2006. 